\title{
Letter from the American Psychiatric Association Meeting
}

\author{
Sydney Brandon
}

I have just returned from the 150th Annual Meeting of the APA in San Diego having received my annual transfusion of Continuing Medical Education points. As usual some of those points were 'earned' at the Jazz video session. The justification for this being that the musicians chosen will have a psychiatric history, usually of drug and/or alcohol misuse. This year we had the incomparable Stan Getz who I was surprised to learn never made a recording unless under the influence of cocaine and had unpredictable mood swings. The drummer Zoot Simms said of Stan Getz, "you couldn't ask to meet a nicer bunch of guys". Perhaps he would now be labelled as multiple personality disorder. The other artist was Joe Pass who almost failed to qualify until it was realised that like Stan he had died of liver disease due to massive alcohol intake. As ever he made the guitar sing so that old ballads sounded as if they were Jazz classics.

It was also possible to attend commercial 'movies' of psychiatric interest or discussions with clips on topics such as The Portrayal of Gays and Lesbians by Hollywood'. These sessions attracted three hours of grade ' $A$ ' credit. I did not attend the movies this year because as usual there were always at least three other sessions I wanted to attend. Starting with a 6.30 am breakfast meeting and going on until $10.00 \mathrm{pm}$ with a multiplicity of meetings to choose from, two days at that pace was enough to convince me of the folly of such activity and I took a morning swim in the San Diego overcast instead of the early morning start.

The trip to San Diego was not cheap, but many psychiatrists from Britain, France, Ireland and Scandinavia resolved this problem by accepting the generous invitation of various drug companies to travel as their guests. So, often complete with spouses, these lucky people were constantly shepherded by their hosts so that they never needed a taxi or a restaurant booking and the social programme was so intense that the delegates were too exhausted to attend the scientific meetings.

The tone of the meeting was less strident than in recent years, I heard no mention of alien abduction or satanic abuse and the discussions, of which there were many, on recovered memory were more considered and agreed that both false memories and recovered memories were real issues which needed further study.

Trauma and its consequences took up a lot of programme time, with major depression and anxiety disorders attracting as much interest as post-traumatic stress disorder (PTSD) as sequelae. PTSD in its own right is still attracting a great deal of attention and a massive amount of research, most of which seemed to be presented at the meeting. Despite concerns about the limits and spectrum of PTSD it is clear that many American practitioners make their main income from such patients.

Attention deficit disorder in children continues to be a major topic and interested not only psychiatrists but the scientologists who held their statutory protest outside the meeting.

Unlike some of their previous efforts the protest was held well away from the building in a park opposite and across a dual carriageway. The massive group were well organised and marched in a continuous oval all bearing banners which called for the abolition of psychiatry and asserted that the educational system of the States had been ruined by the prescription of methylphenidate hydrochlorate which was destroying children's minds. I felt like a man whose assailant had turned to another victim for there was not a word about electroconvulsive therapy. I suspect that the orderly protest owed more to the reputation of the San Diego Police Department than to the wishes of the scientologists.

This year there seemed to be special interest in attention deficit disorder in adults and the careful clinical descriptions certainly accurately described some of my friends and colleagues but few of my patients.

There is still marked preoccupation with the evils of managed care and I felt that morale was low among psychiatrists. Most of the people I talked to complained of the loss of patient contact, for after diagnosis and prescription further visits were not paid for and careful drug monitoring and supportive psychotherapy are things of the past. It took an Act of Congress to get a two day stay for child-birth so you can imagine the attitude of funders to psychiatric disorder. One speaker described an in-patient 
study in a famous psychiatric hospital. When ethical approval for the project was sought the average length of stay was three months, by the time the study started it was one month and a month later it was five days.

Today Health Maintenance Organisations which contract to provide complete medical care have announced that they are giving groups of physicians a monthly drug budget and charging them the full amount of any overspend while allowing them to keep any savings. It is clear that some Health Maintenance Organisations already propose to provide an inadequate budget. Avarice is a powerful incentive even in our caring profession.

It was sad to see doctors streaming through the exhibit hall, avoiding the eyes of the detail men waiting to extol their product and sweeping up pens, key rings and useless trinkets by the dozen. At the stand of one famous 'ethical' drug company a queue of doctors waited to have their photograph taken and merged into an impresstve document which was then fitted into a gllded and glazed frame. The document was a blatant advertisement for the company product which outlined the target symptoms and announced that the doctor, named under his photograph. was expert in this condition. There was a choice of depression or anxiety.

I succumbed to the temptation of a miniature Swiss Army knife which a friend informed me was being given away by one firm. I approached the representative and listened to his account of the alleged virtues of their drug. Eventually I interrupted him and said "It really is shameful but I actually came in the hope of getting a Swiss Army knife". "Don't be embarrassed doctor" came the reply "our industry has created this monster".

The attendance at the meeting was rather low at 15000 , mostly psychiatrists. That feared catastrophic drop in membership has not occurred though there has been a sharp increase in those not paying their dues. Trainees (residents) are attending in greater numbers than ever and are keenly interested in the politics as well as the practice of psychiatry.

My New York friends used to tell me that a psychiatrist was defined as a nice Jewish boy who could not stand the sight of blood. This year the top awards to residents presented at the meeting had their origins in South America, the Far East or the Indian sub-continent.

Despite the problems. American psychiatry is as vigorous and diverse as ever, psychotherapy is no longer in decline and commitment to patients is stronger than ever. I would recommend any psychiatrist to visit the APA at least once in a professional lifetime for we have nothing like it.

Sydney Brandon, 19 Holmfleld Road, Leicester LE2 ISD 